\title{
Recovery in the Canadian Context: Feedback on the Framework for Mental Health Strategy Development
}

\author{
Gillian Mulvale \\ Mental Health Commission of Canada \\ and McMaster University \\ Mary Bartram \\ Mental Health Commission of Canada
}

\begin{abstract}
The Mental Health Commission of Canada is developing a strategy to transform the mental health system in Canada. National consultations held in spring 2009 provided feedback on a proposed framework of goals for the strategy. The first goal discusses a recovery orientation for people living with mental health problems and illnesses. Consultation participants strongly supported a recovery orientation but raised a number of concerns, especially for children, youth, and seniors. In response, the strategy will position recovery as part of a comprehensive approach that includes promoting the best possible mental health and well-being across the lifespan.
\end{abstract}

In May 2006, the Standing Senate Committee on Social Affairs, Science and Technology released the final report of a 3-year study on the mental health system. This landmark document, entitled Out of the Shadows at Last (Kirby \& Keon, 2006), called for the creation of a mental health commission to focus attention on issues of mental health and mental illness in Canada. A key element of the document's vision was that "what is needed is a genuine system that puts people living with mental illness at its centre, with a clear focus on their ability to recover" (Kirby \& Keon, 2006, p. 37).

Gillian Mulvale, Senior Policy Advisor, Mental Health Strategy, Mental Health Commission of Canada, Ottawa, and Clinical Epidemiology and Biostatistics, McMaster University, Hamilton, Ontario; Mary Bartram, Senior Advisor on Government Relations, Mental Health Strategy, Mental Health Commission of Canada, Ottawa.

The opinions expressed in this article are those of the authors and not of the Mental Health Commission of Canada.

Correspondence concerning this article should be addressed to Gillian Mulvale, Mental Health Commission of Canada, 1145 Carling Ave., Suite 7500, Ottawa ON K1Z 7K4. Email: gmulvale@mentalhealthcommission.ca 
Since then, the Mental Health Commission of Canada (MHCC) has been established and is in the process of developing a strategy to transform the mental health system in Canada. There are two phases to developing the strategy. The first phase (see Figure 1) has focused on determining "what" the goals of the mental health strategy should be, by building support through consultations with consumers, family members, policy-makers, and other mental health stakeholders for a draft set of goals for a transformed mental health system. This framework of goals will serve two important purposes: It will present the MHCC's vision for a transformed mental health system to the public, providers, policy-makers, and the research community; and it will guide the second phase of mental health strategy development, which will focus on "how" to achieve the goals.

At the time of writing, the mental health strategy team is nearing completion of the "what" phase. A first set of goals was drafted in September 2008 based on a review of federal, provincial, and territorial mental health policy documents, including Out of the Shadows at Last and policy documents from other countries, and input from the MHCC's eight advisory committees. ${ }^{1}$ The goals were revised following input from the MHCC's consumer council, advisory committees, and board of directors, and from federal, provincial and territorial governments during the fall of 2008. A consultation document on the proposed goals, entitled Toward Recovery and Well-Being: A Framework for a Mental Health Strategy for Canada, was approved

Figure 1

Mental Health Strategy Framework Development - Phase 1 (The WHAT Phase)
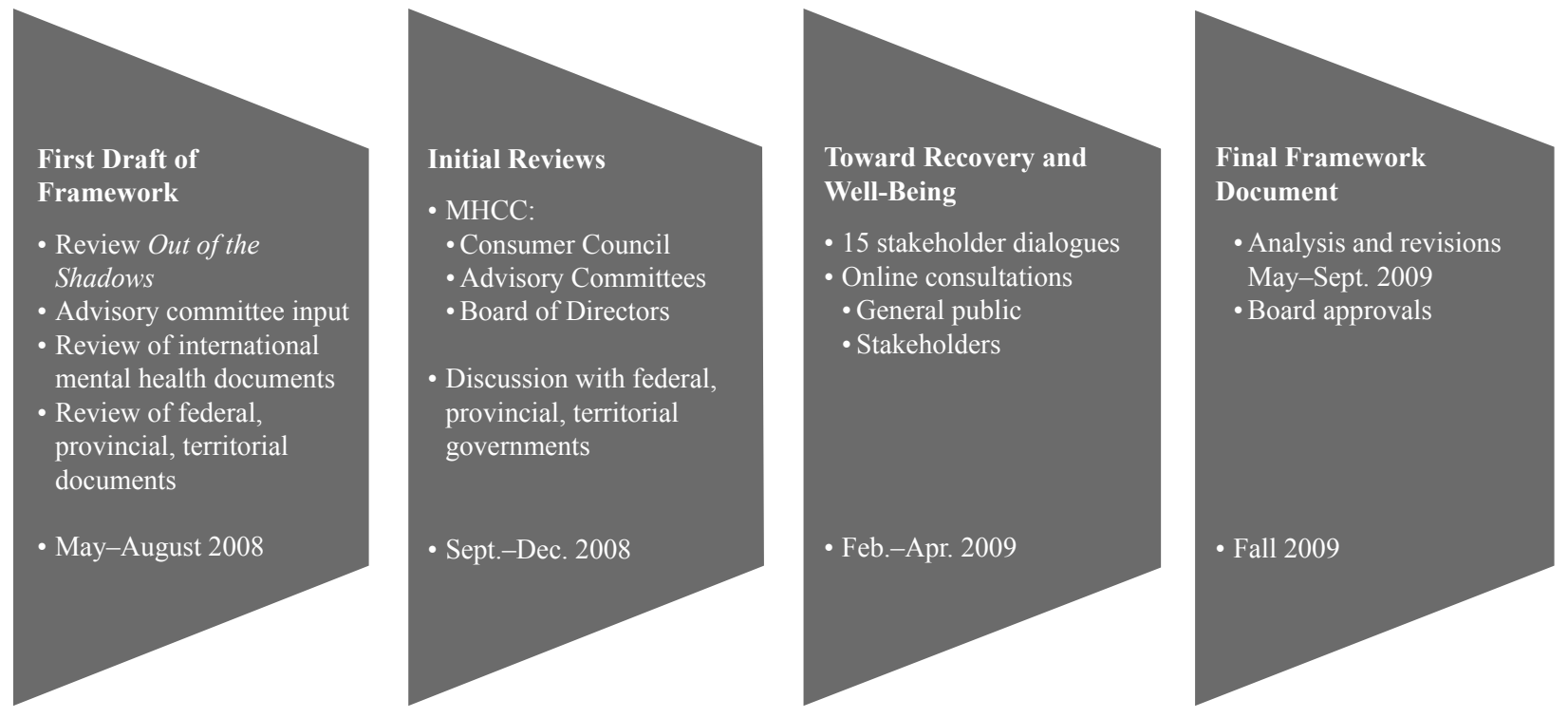

Note. Adapted from "Toward Recovery and Well-Being: A Framework for a Mental Health Strategy for Canada (January 2009 Draft) Public Consultation Report," prepared for the Mental Health Commission of Canada by Ascentum, August 2009. 
by the MHCC board of directors in January 2009. A broad national consultation was held that spring to gauge the degree of support for the proposed goals and to determine how they could be strengthened. The consultations took the form of 15 stakeholder dialogues held across the country, as well as online consultations with approximately 1,700 members of the public and over 350 stakeholder groups.

On the basis of this feedback, the MHCC is finalizing its framework of proposed goals. The document will be made public during the fall of 2009. The revised framework proposes a comprehensive and inclusive approach to mental health system transformation that promotes the mental health and well-being of all Canadians and places a recovery orientation at the centre of reforms for people living with mental health problems and illnesses.

This article summarizes the feedback on the proposed recovery orientation that has been gathered internally from the MHCC consumer council, advisory committees, and board of directors; and externally from federal, provincial, and territorial policy-makers and from public and stakeholder consultations. This feedback includes strong opinions both supporting and raising concerns about adopting a recovery orientation in the Canadian context.

\section{OPINIONS ABOUT A RECOVERY ORIENTATION}

Although support for Out of the Shadows has been widespread, the meaning of recovery in the Canadian context has yet to be systematically discussed. The feedback to date suggests that there is considerable confusion about the meaning of recovery, which points to the need for such a discussion.

Confusion arises because the term recovery applies to so many different concepts in everyday usage. For example, in the Canadian context, recovery may refer to anything from "recovering from a bout of flu" to "recovering the puck" in a hockey game. However, for close to 20 years, the term has had particular meaning for people living with mental health problems and illnesses (Jacobson \& Greenley, 2001). For them, recovery is seen as a journey by which a person comes to live a meaningful life, despite having experienced the "crisis" of a mental illness. Importantly, this understanding of recovery may or may not include clinical recovery. The importance of hope, and of empowering people living with mental health problems or illnesses to set their own recovery goals - to make choices about which treatments (including medication), services, and supports are most helpful to them, and to define for themselves what a meaningful life would look like - are all underlying principles of this view of recovery.

Although there is general agreement about these underlying principles, there is no single, agreed upon definition of the term recovery. To launch a discussion of recovery in the Canadian context, the MHCC built upon the U.S. Substance Abuse and Mental Health Services Administration (SAMHSA) consensus statement, which was based on input from over 110 expert panelists, including mental health consumers, family members, providers, advocates, researchers, managed care and accreditation representatives, state and local public officials, and others. The consensus statement described recovery as "a journey of healing and trans-

formation enabling a person with a mental health problem to live a meaningful life in a community of his or her choice while striving to reach his or her full potential" (SAMHSA, 2004, Background section, para. 4). 


\section{Support for the Concept of Recovery}

The resulting draft framework, Toward Recovery and Well-Being, positioned recovery as a central focus. The recovery concept and its positioning were strongly supported by members of the MHCC's consumer council, which is composed of members of the board of directors and advisory committees who have lived experience of mental health problems and illnesses. This approach also received strong endorsement during the public and stakeholder consultations, with approximately $87 \%$ of both groups supporting a recovery orientation as formulated in the first goal of the proposed framework- "The hope of recovery is available to all" - as a basis for mental health system transformation (see Figure 2). The underlying principles of hope, empowerment, choice, and responsibility were also strongly supported. Other themes that frequently arose were the importance of adopting a person-centred and holistic approach, and the need for communities to foster an environment that supports individuals in their journeys of recovery. There was also support for having services and supports operated by people living with mental health problems and illnesses as a key part of the mental health system.

\section{Figure 2}

\section{Feedback About Recovery Concepts From Online Consultations}

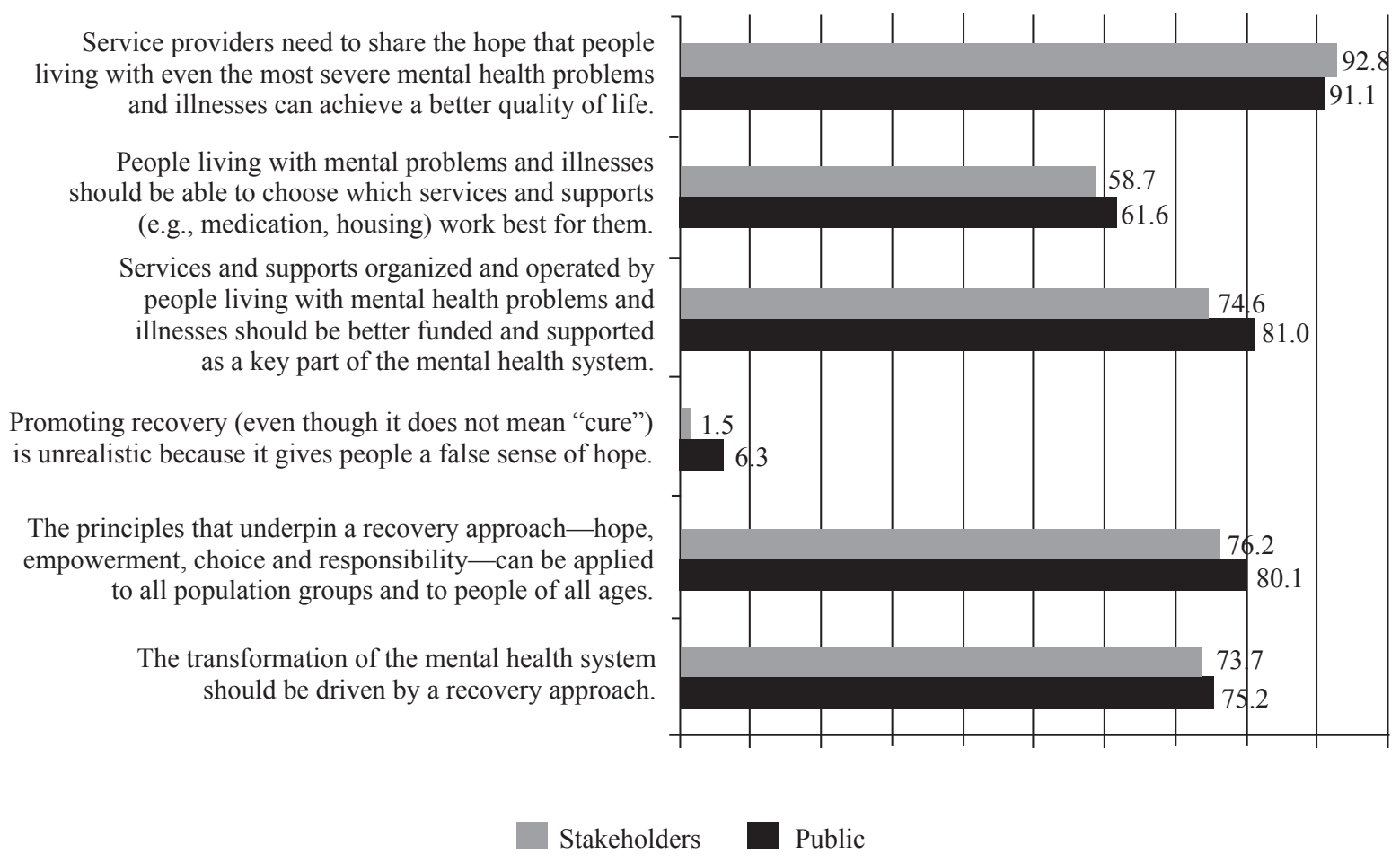

Note. The figure illustrates the percentage of public and stakeholder respondents who indicated a high degree of support for a number of statements that represent different viewpoints on the concept of recovery. The consultations were conducted online, using electronic workbooks. Adapted from "Toward Recovery and Well-Being, Online Consultation Workbook," Mental Health Commission of Canada, February-April 2009. 
At the same time, some members of the stakeholder community, the public, and the MHCC family felt that while recovery was an important concept, there were issues to consider when applying it in the Canadian context.

\section{Concerns About the Recovery Concept}

First, people from a variety of perspectives felt that there was a need to emphasize that no one recovers in isolation. Many felt that having access to appropriate services and supports, and, in some cases, to treatment was a necessary prerequisite for recovery. We are all part of a broader social context that includes family, friends, school, work, and other aspects of community, and this social context is important to an individual's journey of recovery. This social context was a particular concern for First Nations, Inuit, Métis, and other ethnocultural and racialized groups that emphasize the influence of community, culture, socioeconomic circumstances, and discrimination on recovery and well-being - for individuals, for families, and even for whole communities.

For this reason, recovery-oriented services must be responsive to diversity in all its forms, and must take into account the social, political, and historical contexts of different groups. There is also a need to recognize and support the critical role that families may play in promoting recovery. Based on this feedback, the MHCC proposed the following draft definition:

Recovery is understood as a journey of healing that builds on individual, family, social and cultural strengths, and enables people living with mental health problems and illnesses to lead meaningful lives in the community, despite any limitations imposed by their condition. (2009a, p. 21)

Some policy-makers and providers had concerns about recovery being a "has-been" concept — an aging buzzword that would soon pass. For example, some providers felt they were already doing "recovery" and that it was nothing new. At the same time, it seemed that many who used the term might not have been fully adhering to its underlying principles (Piat, Sabetti, \& Couture, 2008). Some providers were uncomfortable with the term recovery and preferred chronic disease management. This concept was more familiar to providers and policy-makers and has some similarities to recovery, in that the goal is to empower the person to use self-care to manage symptoms of an ongoing illness so as to achieve the best quality of life possible.

Other concerns reflected confusion over the meaning of recovery: While recovery is defined in terms of recovering a meaningful life that may or may not include a full clinical recovery, many continued to hear "clinical recovery" or full remission of symptoms. Clinical recovery was not always seen as a realistic objective, and thus the concern was raised that the recovery concept could create false hopes and unrealistic expectations. This concern was greatest for people with debilitating and chronic mental illnesses, and for seniors with deteriorating conditions such as dementia, even though these individuals also stand to benefit from underlying recovery principles such as greater self-determination, improved quality of life, and choice among services. Another concern was that if governments misinterpreted recovery to mean "clinical recovery," those groups seen as least likely to achieve full clinical recovery might be allocated the least funding and services. Therefore, some preferred the concept of "well-being" over "recovery."

The opposite concern was also heard, that the goal as written downplayed the possibility of a cure for some mental illnesses. The applicability of the recovery concept for children and youth was frequently questioned. Some argued that the term recovery is a backward-looking concept that speaks to "recovering something 
that was lost." Child and youth advocates argued that children's identities are still forming throughout childhood and adolescence, and so a more forward-looking concept is needed that speaks to supporting children and youth to develop the best possible mental health and well-being. Recovery principles of empowerment and choice also seemed less relevant for children and youth because their parents and guardians are often the primary decision-makers. Moreover, a focus on recovery might neglect pressing issues for this population, such as early intervention at the first sign of difficulty, support for early childhood development and for families and youth at risk, as well as mental health promotion and mental illness prevention in schools.

Another concern was that access to services is the most pressing need for people living with mental health problems and illnesses. When not enough services are available and more funding is urgently needed, the orientation of services was seen to be of secondary importance.

The final concern was that the recovery concept has traditionally focused on only a small, albeit highly needy, segment of the population - those with the most serious mental illnesses. People believed that a mental health strategy should be about improving the mental health of all Canadians, whether they have a mental illness or not.

\section{A COMPREHENSIVE AND INCLUSIVE APPROACH}

This feedback helped to clarify that what was needed was a framework that could simultaneously reflect the strong endorsement of a recovery orientation - especially among those who live with mental health problems and illnesses - and address the concerns about using the term recovery for specific populations. At the same time, the framework would need to address the relationship between recovery for those with mental illnesses and mental health promotion for all Canadians, and highlight the urgent need for more resources and more effective use of existing resources. Clearly, a comprehensive approach was required.

The comprehensive approach adopted by the Mental Health Commission of Canada recognizes that there are important similarities between the concepts of recovery and well-being. Well-being is reflected in fulfilling one's potential, contributing to the community, and enjoying quality of life across the lifespan. Similarly, the MHCC's definition of recovery calls for enabling people to lead meaningful lives in the community. Further, the recovery principles of hope, empowerment, choice, and responsibility are important to everyone's well-being. Both recovery and well-being are influenced by myriad health and social factors.

There are also similarities in the policies, programs, services, and supports that influence recovery and well-being at any age. For example, while access to medical services and supports can be critical to recovery from mental illness, many would argue that other factors - such as housing, supportive relationships, and resilience - can have at least as much influence on recovery. At the same time, services and supports can be very important for those who do not have a mental illness but who nevertheless are struggling with poor mental health or with other health and social issues.

The comprehensive framework proposed by the MHCC recognizes the parallels between recovery and well-being and is inclusive of all Canadians. It recognizes the clear overlaps between promoting mental health and preventing mental illness among people of all ages, and providing recovery-oriented services and supports for those who require them. The final framework suggests that

Good mental health and well-being is what we want to achieve for everyone. Mental health problems and illnesses can affect anyone, at any age, and everyone can benefit from improved mental health. Many people 
RECOVERY IN THE CANADIAN CONTEXT

living with mental health problems and illnesses will need specialized services, treatments or supports to help them to achieve a better quality of life; but, at the core, when it comes to mental health and well-being, we are all the same - whether we are currently experiencing a mental health problem or illness or not. There

is no us and them. (Mental Health Commission, 2009b, p. 13)

This comprehensive and inclusive approach recognizes that policies, programs, services, and supports create a social context that can promote well-being and recovery for people of all ages, at the individual, family, and community levels. Such an approach will also address many of the social determinants of health that have long been advocated by people living with mental health problems and illnesses, such as having "a home, a job, a friend."

\section{IMPLICATIONS}

Taken together, the goals proposed in the draft framework, Toward Recovery and Well-Being, combine to envision a system in which all Canadians can choose from among a comprehensive set of appropriate services and supports. When care is required, people will be partners in the care team and active participants in decision-making. Regardless of their age, people can embark on a "journey of healing" toward recovery and well-being. Even those with severe and persistent mental illness, who may not achieve full "clinical recovery," can be empowered to live meaningful lives in the community. All of this means that policies, programs, services, and supports must be centred on people and their families in a flexible way that can respond to their needs, circumstances, and preferences. To be effective, programs and services must be based on appropriate evidence, respond to diversity, and address the cultural factors and power imbalances that can obstruct access.

It also means that service providers will encourage people of all ages to voice their goals for recovery and well-being and their choice of services and supports, and to articulate what works best for them. Funding agencies and providers will help to break down the silos that create barriers to person-centred, seamless care - that addresses the full continuum of each person's needs at every stage of life.

A comprehensive approach points to the need to adopt "whole of government approaches" to work across the various health, social services, and other departments and agencies of government (e.g., education, justice, corrections, finance, housing, sports and recreation). Governments and the private sector will need to remove obstacles to the smooth integration of services in order to promote mental health, prevent mental illness, and address people's multiple needs across the lifespan in settings such as schools, workplaces, long-term care settings, families, and communities. This includes targeted early intervention programs for those with emerging mental health problems, particularly children and youth.

Furthermore, a comprehensive approach will challenge researchers to carefully examine underlying conceptual frameworks in which unintended "us" versus "them" thinking may be subtly embedded, so as to avoid polarized debates about the importance of mental health promotion versus recovery, social determinants versus treatment approaches, and so on. A comprehensive approach requires that all elements of the framework be appropriately balanced for each sector (e.g., health care, schools, workplaces) and constituency group (e.g., children, youth, seniors).

Most importantly, a comprehensive approach has much to offer people living with mental health problems and illnesses and their families, and can enrich the lives of all Canadians. It promises to advance social 
inclusion and reduce stigma, to create a social context that will promote mental health and well-being, and to offer recovery-oriented services and supports.

\section{NEXT STEPS}

The Mental Health Commission of Canada is now moving into the "how" phase of strategy development (see Figure 3). This will involve conducting research and consultations to determine how each of the goals will be achieved in various settings (e.g., families, communities, workplaces, schools, health and social care delivery, the justice system) and among various populations within Canada. The MHCC will draw on research and advice from its advisory committees, conduct additional research and consultations on cross-cutting themes (e.g., recovery, mental health promotion, funding, human resources, research, data, and evaluation), and gather input from governments and other sectors. The framework will be used to ensure

\section{Figure 3}

Mental Health Strategy Framework Development - Phase 2 (The HOW Phase)

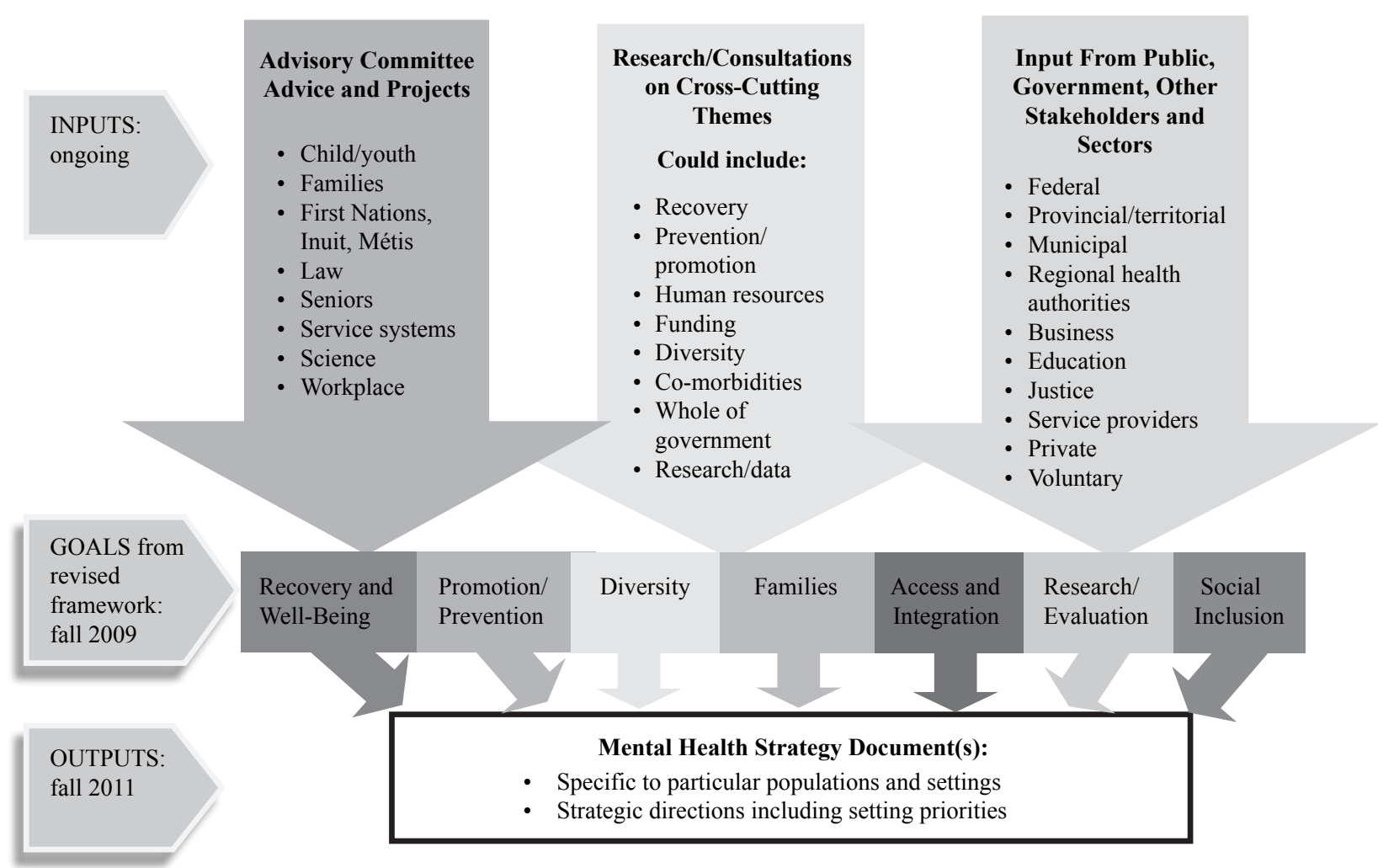

Note. Adapted from "Toward Recovery and Well-Being: A Framework for a Mental Health Strategy for Canada (January 2009 Draft) Public Consultation Report," prepared for the Mental Health Commission of Canada by Ascentum, August 2009. 


\section{RECOVERY IN THE CANADIAN CONTEXT}

that the strategic action plan the MHCC will propose aligns with the goals for a transformed mental health system and that a comprehensive approach to transformation is adopted - one that fosters recovery and well-being in the Canadian context.

\section{NOTE}

1. The eight advisory committees are Child and Youth; Family Caregivers; First Nations, Inuit and Métis; Seniors; Mental Health and the Law; Service Systems; Science; and Workforce.

\section{RÉSUMÉ}

La Commission de la santé mentale du Canada (CSMC) élabore actuellement une stratégie pour transformer le système de soins de santé mentale canadien. Des consultations pancanadiennes tenues au printemps 2009 ont permis d'obtenir des commentaires sur un cadre proposé contenant des objectifs pour la stratégie. Le premier objectif traite d'une orientation axée sur le rétablissement pour les personnes vivant avec des maladies et des troubles mentaux. Les participants et participantes aux consultations ont fortement appuyé cette orientation, mais ont soulevé un certain nombre de préoccupations, notamment pour ce qui est des enfants, des jeunes et des personnes âgées. En réponse, la stratégie placera le rétablissement au sein d'une approche globale comprenant notamment la promotion du meilleur état de santé mentale et de bienêtre mental possible tout au long de la vie.

\section{REFERENCES}

Jacobson, N., \& Greenley, D. (2001). What is recovery? A conceptual model and explication. Psychiatric Services, $52(4), 482-485$

Kirby, M.J.L., \& Keon, W.J. (2006). Out of the shadows at last: Transforming mental health, mental illness and addiction services in Canada. Ottawa: Senate Standing Committee on Social Affairs, Science and Technology.

Mental Health Commission of Canada. (2009a). Toward recovery and well-being: A framework for a mental health strategy for Canada. Draft. Retrieved from http://www.mentalhealthcommission.ca/SiteCollectionDocuments/ Key_Documents/en/2009/Mental_Health_ENG.pdf

Mental Health Commission of Canada. (2009b, in press). Toward recovery and well-being: A framework for a mental health strategy for Canada.

Piat, M., Sabetti, J., \& Couture, A. (2008). Do consumers use the word recovery? Psychiatric Services, 59(4), 446-447. Substance Abuse and Mental Health Services Administration. (2004). National consensus statement on mental health recovery. Retrieved from http://mentalhealth.samhsa.gov/publications/allpubs/sma05-4129/ 